\title{
Facilitate recycle activities via ICT and physical approach
}

\begin{abstract}
Recycle, reuse and reduce are commonly heard as the activities to support for green environment. However, without or lack of self awareness and voluntary to contribute to the green it can cause a failure effort and projects from the government and other sectors. Furthermore, the public could not be expected to keep recycling without enough motivation, assistance and facility. Alternatively, we proposed a web application as an e-platform for the community and business entity including shopping mall, green business and other agencies to support and collaborate between each other in supporting for recycle and reuse. We have investigated through survey and interview with those involved including the public and representatives from the selected shopping malls to collect data of the current scenario regarding their awareness and willingness to contribute to green. Our solution called eReward for Recyclers purposely to motivate people to recycle their used items from home at one stop recycling centre by collaborating with shopping malls. Lastly, we wanted to connect people from the green business including recycle factory, reused company and welfare organization to the recycle centre for them to collect mass recycled items to be reused for their purposes.
\end{abstract}

Keyword: E-reward application; Recycle; Reuse; Green community; Online platform 